\title{
Dexmedetomidine as a Sedative Agent in Critically III Patients: A Meta-Analysis of Randomized Controlled Trials
}

\author{
Laura Pasin ${ }^{1}$, Teresa Greco ${ }^{1}$, Paolo Feltracco ${ }^{2}$, Annalisa Vittorio ${ }^{1}$, Caetano Nigro Neto ${ }^{1}$, Luca Cabrini ${ }^{1}$, \\ Giovanni Landoni ${ }^{1,3 *}$, Gabriele Finco ${ }^{4}$, Alberto Zangrillo ${ }^{1}$
}

1 Anesthesia and Intensive Care Department, San Raffaele Scientific Institute, Milan, Italy, 2 Department of Pharmacology and Anesthesiology, University Hospital of Padua, Padua, Italy, 3 Outcomes Research Consortium, Cleveland, Ohio, United States of America, 4 Department of Medical Sciences "M. Aresu", Cagliari University, Cagliari, Italy

\begin{abstract}
Introduction: The effect of dexmedetomidine on length of intensive care unit (ICU) stay and time to extubation is still unclear.

Materials and Methods: Pertinent studies were independently searched in BioMedCentral, PubMed, Embase, and the Cochrane Central Register of clinical trials (updated February first 2013). Randomized studies (dexmedetomidine versus any comparator) were included if including patients mechanically ventilated in an intensive care unit (ICU). Co-primary endpoints were the length of ICU stay (days) and time to extubation (hours). Secondary endpoint was mortality rate at the longest follow-up available.

Results: The 27 included manuscripts ( 28 trials) randomized 3,648 patients (1,870 to dexmedetomidine and 1,778 to control). Overall analysis showed that the use of dexmedetomidine was associated with a significant reduction in length of ICU stay (weighted mean difference $(W M D)=-0.79[-1.17$ to -0.40$]$ days, $p$ for effect $<0.001$ ) and of time to extubation $(\mathrm{WMD}=-2.74[-3.80$ to -1.65$]$ hours, $\mathrm{p}$ for effect $<0.001)$. Mortality was not different between dexmedetomidine and controls (risk ratio $=1.00$ [0.84 to 1.21$]$, p for effect $=0.9$ ). High heterogeneity between included studies was found.

Conclusions: This meta-analysis of randomized controlled studies suggests that dexmedetomidine could help to reduce ICU stay and time to extubation, in critically ill patients even if high heterogeneity between studies might confound the interpretation of these results.
\end{abstract}

Citation: Pasin L, Greco T, Feltracco P, Vittorio A, Neto CN, et al. (2013) Dexmedetomidine as a Sedative Agent in Critically III Patients: A Meta-Analysis of Randomized Controlled Trials. PLoS ONE 8(12): e82913. doi:10.1371/journal.pone.0082913

Editor: Mercedes Susan Mandell, University of Colorado, United States of America

Received July 16, 2013; Accepted October 29, 2013; Published December 31, 2013

Copyright: (c) 2013 Pasin et al. This is an open-access article distributed under the terms of the Creative Commons Attribution License, which permits unrestricted use, distribution, and reproduction in any medium, provided the original author and source are credited.

Funding: The study was conducted exclusively with departmental sources. The funders had no role in study design, data collection and analysis, decision to publish, or preparation of the manuscript.

Competing Interests: Giovanni Landoni is a PLOS ONE Editorial Board member. This does not alter the authors adherence to all the PLOS ONE policies on sharing data and materials.

*E-mail: landoni.giovanni@hsr.it

\section{Introduction}

Dexmedetomidine was approved by the Food and Drug Administration (FDA) at the end of 1999 as a short-term medication $(<24$ hours) for analgesia and sedation in mechanical ventilated intensive care unit (ICU) patients. In 2008, the FDA approved a new indication in non intubated patients requiring sedation before and/or during surgical and non-surgical procedures. Dexmedetomidine is a highly selective a2-adrenergic receptor agonist, which binds to transmembrane $G$ proteinbinding adrenoreceptors in the periphery $(\alpha 2 \mathrm{~A})$, brain and spinal cord $(\alpha 2 \mathrm{~B}, \alpha 2 \mathrm{C})$ tissues [1]. In contrast to other sedative agents, dexmedetomidine, by acting on a2 receptors in the locus caeruleus [2], has potential analgesic effects [3] without respiratory depression [4,5]. Only one meta-analysis of randomized controlled trials (RCTs) [6] was published so far: Tan and Ho reported a reduction in length of ICU stay, but not in duration of time to extubation when dexmedetomidine was compared with alternative sedative agents.

Since several RCTs [7-14], including two large ones [8], were recently published, and one further RCT [15] was not included in the previous meta-analysis [6] we decided to perform an updated meta-analysis of all the RCTs ever performed on dexmedetomidine versus any comparator in the ICU setting to evaluate time to extubation, ICU stay and survival.

\section{Materials and Methods}

\section{Search Strategy}

Pertinent studies were independently searched in BioMedCentral, PubMed, Embase, and the Cochrane Central Register of clinical trials (updated February $1^{\text {st }}$ 2013) by four trained investigators. The full PubMed search strategy aimed to include any RCTs ever performed in humans with dexmedetomidine in 

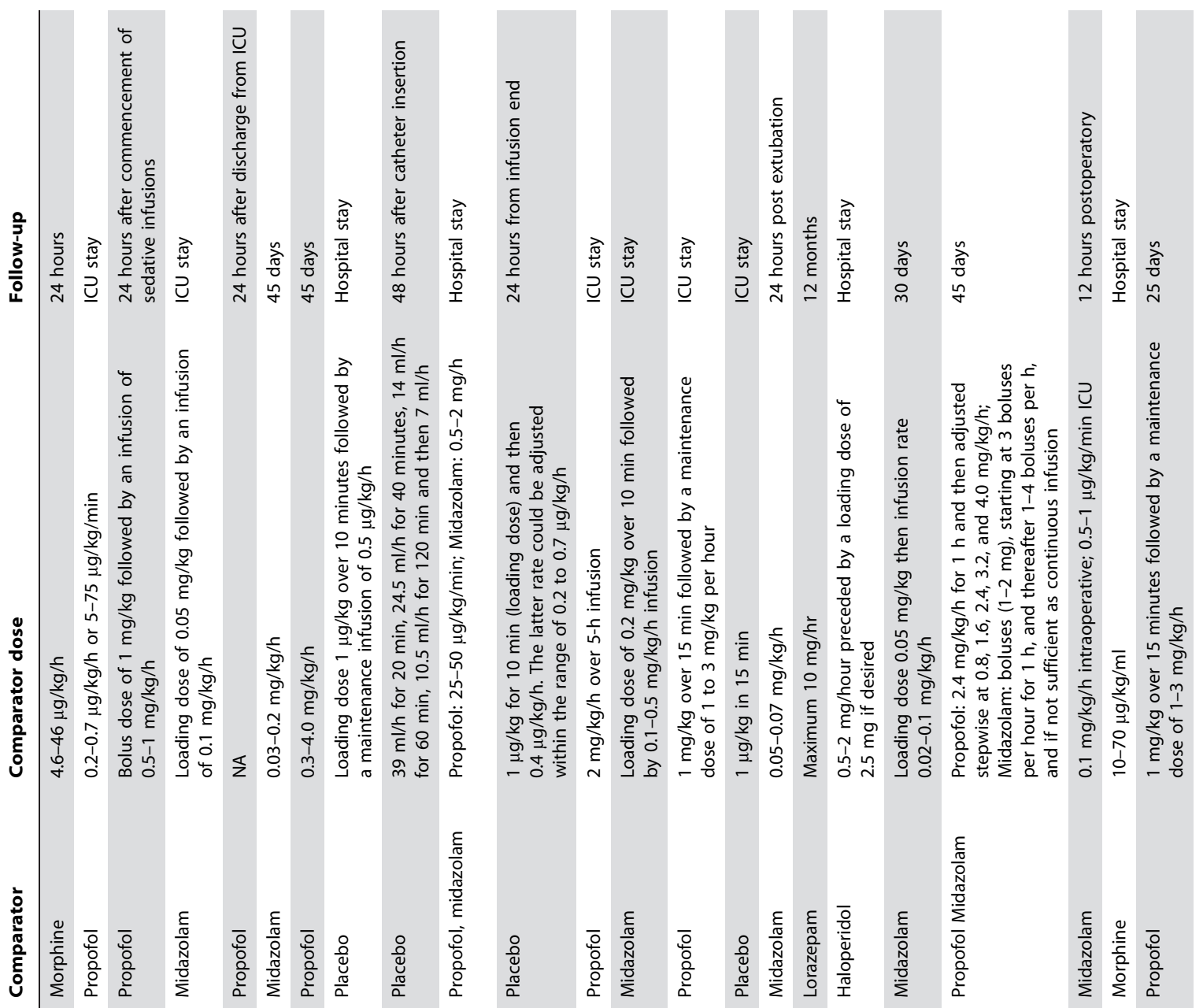

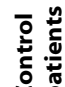

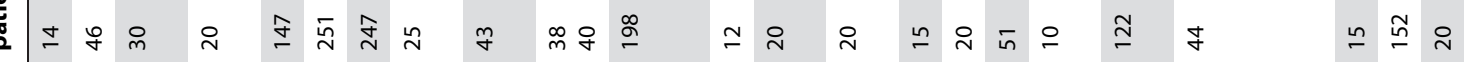

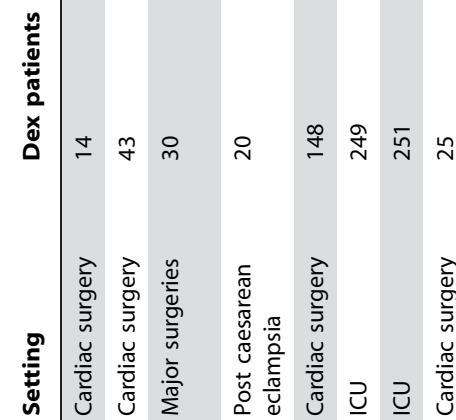

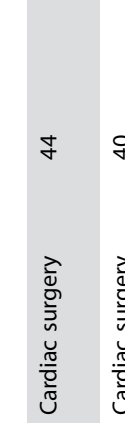
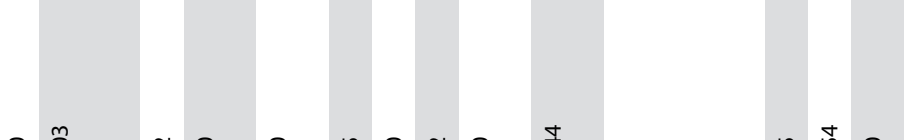

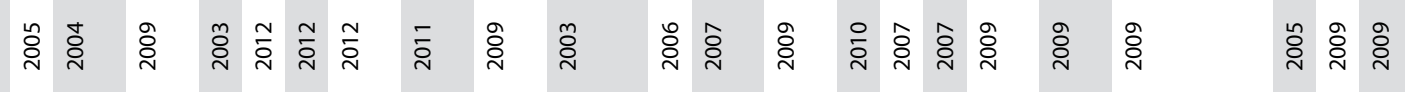




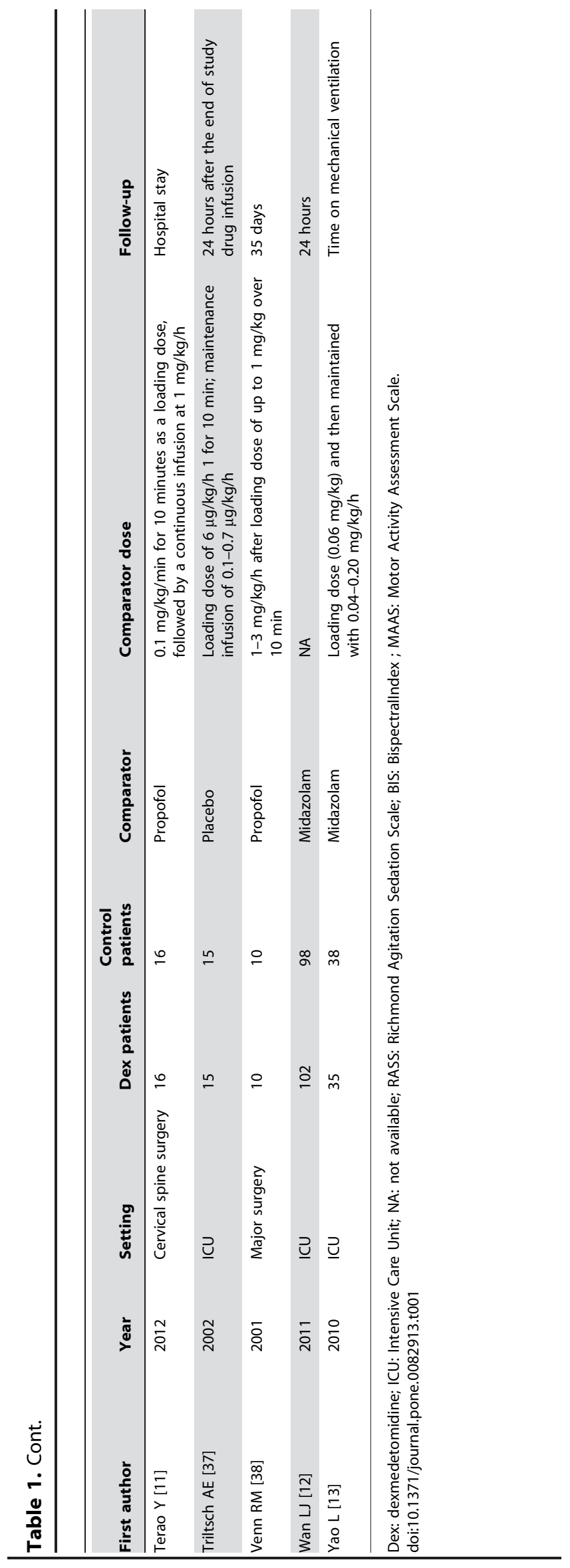

any clinical setting and is presented in the supplemental material (Text S1). In addition, we employed backward snowballing (i.e., scanning of references of retrieved articles and pertinent reviews) and contacted international experts for further studies with no language restriction.

\section{Study Selection}

References were first independently examined at a title/abstract level by four investigators, with divergences resolved by consensus, and then, if potentially pertinent, retrieved as complete articles. The following inclusion criteria were used for potentially relevant studies: random allocation to treatment (dexmedetomidine versus any comparator with no restrictions on dose or time of administration); studies involving patients who required mechanical ventilation in an ICU. The exclusion criteria were duplicate publications (in this case we referred to the first article published while retrieved data from the article with the longest follow-up available), non-adult patients and lack of data on all of the following: ICU stay, time to extubation and mortality. Two investigators independently assessed compliance to selection criteria and selected studies for the final analysis, with divergences resolved by consensus.

\section{Data Abstraction and Study}

Baseline, procedural, and outcome data were independently abstracted by four trained investigators (table 1 and table 2). If a trial reported multiple comparisons [25,34], the comparators were aggregated as a single control group. At least two separate attempts at contacting original authors were made in cases of missing data. The co-primary endpoints of the present review were the length of ICU stay (days) and time to extubation (hours from randomization to extubation).

The secondary endpoint was mortality rate at the longest followup available. Adverse effects (hypotension and bradycardia as per author definition) were also analysed. Further endpoints included the number of patients requiring rescue doses of analgesic (opioids) or sedative (propofol, benzodiazepines, or any antipsychotics) drugs and the number of patients completely comfortable during ICU stay.

The internal validity and risk of bias of included trials was appraised by two independent reviewers according to the latest version of the "Risk of bias assessment tool" developed by The Cochrane collaboration [16], with divergences resolved by consensus. Publication bias was assessed by visually inspecting funnel plots and scatter plots and by analytical appraisal based on the Egger's linear regression test and on the Peters' test for asymmetry. According to the Egger [17] or Peters [18] methods for publication bias evaluation, a two-sided $p$ value of 0.10 or less was regarded as significant.

\section{Data Analysis and Synthesis}

Computations were performed with Stata release 11, College Station, TX) and SAS 2002-08 program (release 9.2, SAS Institute, Inc, Cary, NC). Hypothesis of statistical heterogeneity was tested by means of Cochran Q test, with statistical significance set at the two-tailed 0.10 level, whereas extent of statistical consistency was measured with $\mathrm{I}^{2}$, defined as $100 \% \times(\mathrm{Q}-\mathrm{df}) / \mathrm{Q}$, where $\mathrm{Q}$ is Cochran's heterogeneity statistic and df the degrees of freedom. Binary outcomes from individual studies were analysed to compute individual and pooled risk ratio ( $R R$ ) with pertinent $95 \%$ confidence interval (CI), by means of inverse variance method and with a fixed-effect model in case of low statistical inconsistency $\left(\mathrm{I}^{2}<25 \%\right)$ or with random-effect model (which better accommodates clinical and statistical variations) in case of 
Table 2. Doses, sedation scales and target sedation levels.

\begin{tabular}{|c|c|c|c|c|}
\hline First author & Study endpoint & Dexmedetomidine dose & Start study drug & Stop study drug \\
\hline Aziz NA [7] & Sedation quality & $0.03-0.25 \mu \mathrm{g} / \mathrm{kg} / \mathrm{h}$ & ICU arrival & After 24 hours \\
\hline Corbett SM [17] & Sedation quality & $\begin{array}{l}\text { Loading dose of } 1 \mu \mathrm{g} / \mathrm{kg} \text { in } 15 \mathrm{~min} \text {, } \\
\text { followed by a } 0.4 / \mu \mathrm{g} / \mathrm{kg} / \mathrm{h} \text { infusion }\end{array}$ & During surgery, after CPB & $\begin{array}{l}\text { Propofol was discontinued before } \\
\text { extubation while dexmedetomidine } \\
\text { was continued for up to } 1 \text { hour after } \\
\text { extubation }\end{array}$ \\
\hline Elbaradie S [22] & Sedation quality & $\begin{array}{l}\text { Loading dose of } 2.5 \mu \mathrm{g} / \mathrm{kgin} 10 \mathrm{~min} \\
\text { followed by a } 0.2-0.5 \mu \mathrm{g} / \mathrm{kg} / \mathrm{h} \text { infusion }\end{array}$ & ICU arrival & Before extubation \\
\hline Esmaoglu A [23] & Sedation quality & $\begin{array}{l}\text { Loading dose of } 1 \mu \mathrm{g} / \mathrm{kg} \text { in } 20 \mathrm{~min} \\
\text { followed by a0.7 } \mu \mathrm{g} / \mathrm{kg} / \mathrm{h} \text { infusion }\end{array}$ & ICU arrival & NA \\
\hline Herr DL [24] & Sedation quality & $\begin{array}{l}\text { Loading dose of } 1 \mu \mathrm{g} / \mathrm{kg} \text { in } 20 \mathrm{~min} \\
\text { followed by a0.4 } \mu \mathrm{g} / \mathrm{kg} / \mathrm{h} \text { infusion. } \\
\text { After transfer to the ICU, the infusion rate was } \\
\text { titrated in the range of } 0.2 \text { to } 0.7 \mu \mathrm{g} / \mathrm{kg} / \mathrm{h}\end{array}$ & Sternal closure & $6-24$ hours after extubation \\
\hline $\begin{array}{l}\text { Jakob SM } \\
\text { MIDEX [8] }\end{array}$ & Sedation quality & $0.2-1.4 \mu \mathrm{g} / \mathrm{kg} / \mathrm{h}$ & $\begin{array}{l}\text { Within } 72 \text { hours after ICU } \\
\text { admission }\end{array}$ & Extubation, 14 days maximum \\
\hline $\begin{array}{l}\text { Jakob SM } \\
\text { PRODEX [8] }\end{array}$ & Sedation quality & $0.2-1.4 \mu \mathrm{g} / \mathrm{kg} / \mathrm{h}$ & $\begin{array}{l}\text { Within } 72 \text { hours after ICU } \\
\text { admission }\end{array}$ & Extubation, 14 days maximum \\
\hline Khalil MA [14] & Sedation quality & $\begin{array}{l}\text { Loading dose of } 1 \mu \mathrm{g} / \mathrm{kg} \text { in } 10 \text { minutes } \\
\text { followed by a } 0.5 \mu \mathrm{g} / \mathrm{kg} / \mathrm{h} \text { infusion }\end{array}$ & $\begin{array}{l}\text { After induction of general } \\
\text { anaesthesia }\end{array}$ & $\begin{array}{l}\text { After stabilization of haemodynamics } \\
\text { in the ICU }\end{array}$ \\
\hline Leino K [9] & Renal effects & $\begin{array}{l}\text { Five-step infusion of } 4 \mu \mathrm{g} / \mathrm{ml} \text { with the following } \\
\text { decreasing infusion rate: } 39 \mathrm{ml} / \mathrm{h} \text { for } 20 \mathrm{~min} \text {, } \\
24.5 \mathrm{ml} / \mathrm{h} \text { for } 40 \mathrm{~min}, 14 \mathrm{ml} / \mathrm{h} \text { for } 60 \mathrm{~min} \text {, } \\
10.5 \mathrm{ml} / \mathrm{h} \text { for } 120 \mathrm{~min} \text { and then } 7 \mathrm{ml} / \mathrm{h} \text { (rates } \\
\text { needed to achieve a pseudo steady-state } \\
\text { plasma concentration of } 0.60 \mu \mathrm{g} / \mathrm{ml} \text { ) }\end{array}$ & $\begin{array}{l}\text { Immediately after } \\
\text { anaesthesia induction }\end{array}$ & $4 \mathrm{~h}$ after ICU arrival \\
\hline Maldonado JR [25] & Sedation quality & $\begin{array}{l}\text { Loading dose of } 0,4 \mu \mathrm{g} / \mathrm{kg} \text { followed by } \\
0.2-0.7 \mu \mathrm{g} / \mathrm{kg} / \mathrm{h}\end{array}$ & After CPB weaning & Maximum $24 \mathrm{~h}$ \\
\hline Martin E [26] & Sedation quality & $\begin{array}{l}\text { Loading dose of } 1 \mu \mathrm{g} / \mathrm{kg} \text { in } 10 \mathrm{~min} \text { followed } \\
\text { by } 0.4 \mu \mathrm{g} / \mathrm{kg} / \mathrm{h} \text {. The latter rate could be } \\
\text { adjusted within the range of } 0.2 \text { to } 0.7 \mu \mathrm{g} / \mathrm{kg} / \mathrm{h}\end{array}$ & $\begin{array}{l}\text { Within } 1 \text { hour after ICU } \\
\text { admission }\end{array}$ & $\begin{array}{l}\text { For a minimum of } 6 \text { hours post } \\
\text { extubation; total time was }<24 \text { hours }\end{array}$ \\
\hline Memis D [27] & Gastric emptying & $\begin{array}{l}\text { Loading dose of } 2.5 \mu \mathrm{g} / \mathrm{kg} \text { in } 10 \mathrm{~min} \text { followed } \\
\text { by } 0.2 \mu \mathrm{g} \mathrm{kg} / \mathrm{h} \text { over } 5 \mathrm{~h} \text { infusion }\end{array}$ & $\begin{array}{l}\text { Within } 4 \text { hours after ICU } \\
\text { admission }\end{array}$ & 5 hours \\
\hline Memis D [28] & $\begin{array}{l}\text { Inflammatory } \\
\text { responses and gastric } \\
\text { intramucosal pH }\end{array}$ & $\begin{array}{l}\text { Loading dose of } 1 \mu \mathrm{g} / \mathrm{kg} \text { in } 10 \mathrm{~min} \text { followed by } \\
0.2-2.5 \mu \mathrm{g} / \mathrm{kg} \text { over } 24 \mathrm{~h} \text { infusion }\end{array}$ & $\mathrm{ICU}$ & NA \\
\hline Memis D [29] & $\begin{array}{l}\text { Indocyanine green } \\
\text { elimination }\end{array}$ & $\begin{array}{l}\text { Loading dose of } 1 \mu \mathrm{g} / \mathrm{kg} \text { in } 10 \mathrm{~min} \text { followed } \\
\text { by a maintenance of } 0.2-2.5 \mu \mathrm{g} / \mathrm{kg} / \mathrm{h}\end{array}$ & NA & 24 hours \\
\hline Menda F [10] & $\begin{array}{l}\text { Haemodynamic } \\
\text { response to } \\
\text { endotracheal } \\
\text { intubation }\end{array}$ & $1 \mu \mathrm{g} / \mathrm{kg}$ in $15 \mathrm{~min}$ & Anaesthesia induction & NA \\
\hline Ozkan N [30] & $\begin{array}{l}\text { Haemodynamics and } \\
\text { mixed venous oxygen } \\
\text { saturation }\end{array}$ & $\begin{array}{l}\text { Loading dose of } 1 \mu \mathrm{g} / \mathrm{kg} \text { followed by } \\
0.2-0.4 \mu \mathrm{g} / \mathrm{kg} / \mathrm{h}\end{array}$ & Anaesthesia induction & NA \\
\hline $\begin{array}{l}\text { Pandharipande PP } \\
\text { [31] }\end{array}$ & Sedation quality & Maximum $1.5 \mu \mathrm{g} / \mathrm{kg} / \mathrm{hr}$ & $\mathrm{ICU}$ & $\begin{array}{l}\text { Until extubation, for maximum } \\
120 \text { hours }\end{array}$ \\
\hline Reade MC [32] & Sedation quality & $\begin{array}{l}\text { Loading dose of } 1.0 \mu \mathrm{g} / \mathrm{kg} \text { in } 20 \mathrm{~min} \text { (if desired) } \\
\text { followed by } 0.2-0.7 \mu \mathrm{g} / \mathrm{kg} / \mathrm{hour}\end{array}$ & $\mathrm{ICU}$ & $\begin{array}{l}\text { As long as clinically indicated, including } \\
\text { following extubation if required }\end{array}$ \\
\hline Riker RR [33] & Sedation quality & $\begin{array}{l}\text { Loading dose of } 1 \mu \mathrm{g} / \mathrm{kg} \text { followed by } \\
0.2-1.4 \mu \mathrm{g} / \mathrm{kg} / \mathrm{h}\end{array}$ & $\begin{array}{l}\text { Within } 96 \text { hours after } \\
\text { intubation }\end{array}$ & Extubation, 30 days maximum \\
\hline Ruokonen E [34] & Sedation quality & $\begin{array}{l}0.8 \mu \mathrm{g} / \mathrm{kg} / \mathrm{h} \text { for } 1 \mathrm{~h} \text { and then adjusted } \\
\text { stepwise at } 0.25,0.5,0.8,1.1 \text {, and } 1.4 \mu \mathrm{g} / \mathrm{kg} / \mathrm{h}\end{array}$ & $\begin{array}{l}\text { Within } 72 \text { hours after ICU } \\
\text { admission }\end{array}$ & Maximum 14 days \\
\hline Sahin N [15] & $\begin{array}{l}\text { Sedation quality and } \\
\text { haemodynamics }\end{array}$ & $\begin{array}{l}0.4 \mu \mathrm{g} / \mathrm{kg} / \mathrm{h} \text { intraoperative; } 0.2-0.4 \mu \mathrm{g} / \mathrm{kg} / \mathrm{h} \\
\text { in ICU }\end{array}$ & Anesthesia induction & 45 hours after extubation \\
\hline Shehabi Y [35] & Sedation quality & $0.1-0.7 \mu \mathrm{g} / \mathrm{kg} / \mathrm{ml}$ & $\begin{array}{l}\text { Within } 1 \text { hour after ICU } \\
\text { admission }\end{array}$ & $\begin{array}{l}\text { Removal of chest drains, maximum } \\
48 \text { hours }\end{array}$ \\
\hline Tasdogan M [36] & $\begin{array}{l}\text { Inflammatory } \\
\text { responses and intra } \\
\text { abdominal pressure }\end{array}$ & $\begin{array}{l}\text { Loading dose of } 1 \mu \mathrm{g} / \mathrm{kg} \text { in } 10 \mathrm{~min} \text { followed } \\
\text { by } 0.2-2.5 \mu \mathrm{g} / \mathrm{kg} / \mathrm{h}\end{array}$ & ICU arrival & 24 hours \\
\hline Terao Y [11] & Sedation quality & $\begin{array}{l}\text { Loading dose of } 0.1 \mu \mathrm{g} / \mathrm{kg} / \mathrm{min} \text { in } 10 \text { minutes } \\
\text { followed by } 0.4 \mu \mathrm{g} / \mathrm{kg} / \mathrm{h}\end{array}$ & ICU arrival & First postoperative morning \\
\hline
\end{tabular}


Table 2. Cont.

\begin{tabular}{lllll}
\hline First author & Study endpoint & Dexmedetomidine dose & Start study drug & Stop study drug \\
\hline Triltsch AE [37] & Sedation quality & $\begin{array}{l}\text { Loading dose of } 6 \mu \mathrm{g} / \mathrm{kg} / \mathrm{h} \text { in } 10 \mathrm{~min} \text { followed } \\
\text { by } 0.1-0.7 \mu \mathrm{g} / \mathrm{kg} / \mathrm{h}\end{array}$ & $\begin{array}{l}\text { Within } 1 \text { hour after ICU } \\
\text { admission }\end{array}$ & $\begin{array}{l}6-7 \text { hours after extubation, maximum } \\
\text { overall } 72 \mathrm{~h}\end{array}$ \\
Venn RM [38] & Sedation quality & $\begin{array}{l}\text { Loading dose of } 2,5 \mu \mathrm{g} / \mathrm{kg} / \mathrm{h} \text { followed by } \\
0,2-2,5 \mu \mathrm{g} / \mathrm{kg} / \mathrm{h}\end{array}$ & $\mathrm{ICU}$ arrival & Extubation \\
& Sedation quality & $\mathrm{NA}$ & $\mathrm{NA}$ & $\mathrm{NA}$ \\
Wan LJ [12] & Sedation quality & $\begin{array}{l}\text { Loading dose of } 1 \mu \mathrm{g} / \mathrm{kg} \text { in } 10 \mathrm{~min} \text { followed by } \\
0.2-0.7 \mu \mathrm{g} / \mathrm{kg} / \mathrm{h}\end{array}$ & $\mathrm{NA}$ & $\mathrm{NA}$ \\
Yao L [13] & & & & \\
\hline
\end{tabular}

ICU: Intensive Care Unit; CPB: cardiopulmonary bypass; NA: not available.

doi:10.1371/journal.pone.0082913.t002

moderate or high statistical inconsistency $\left(\mathrm{I}^{2}>25 \%\right)$. Standardized mean differences (SMD), or weighted mean difference (WMD), and $95 \%$ confidence intervals were computed for continuous variables using the same models as just described. To evaluate if the small study effect had an influence on the treatment effect estimate, in case of evidence of between-study heterogeneity $\left(\mathrm{I}^{2}>25\right)$, we compared the results of both fixed and random effect models. Sensitivity analyses were performed by sequentially removing each study and reanalysing the remaining dataset (producing a new analysis for each study removed) and by analysing only data from blinded studies and studies with low risk of bias.

Statistical significance was set at the two-tailed 0.05 level for hypothesis testing. Unadjusted p values are reported throughout. This study was performed in compliance with The Cochrane

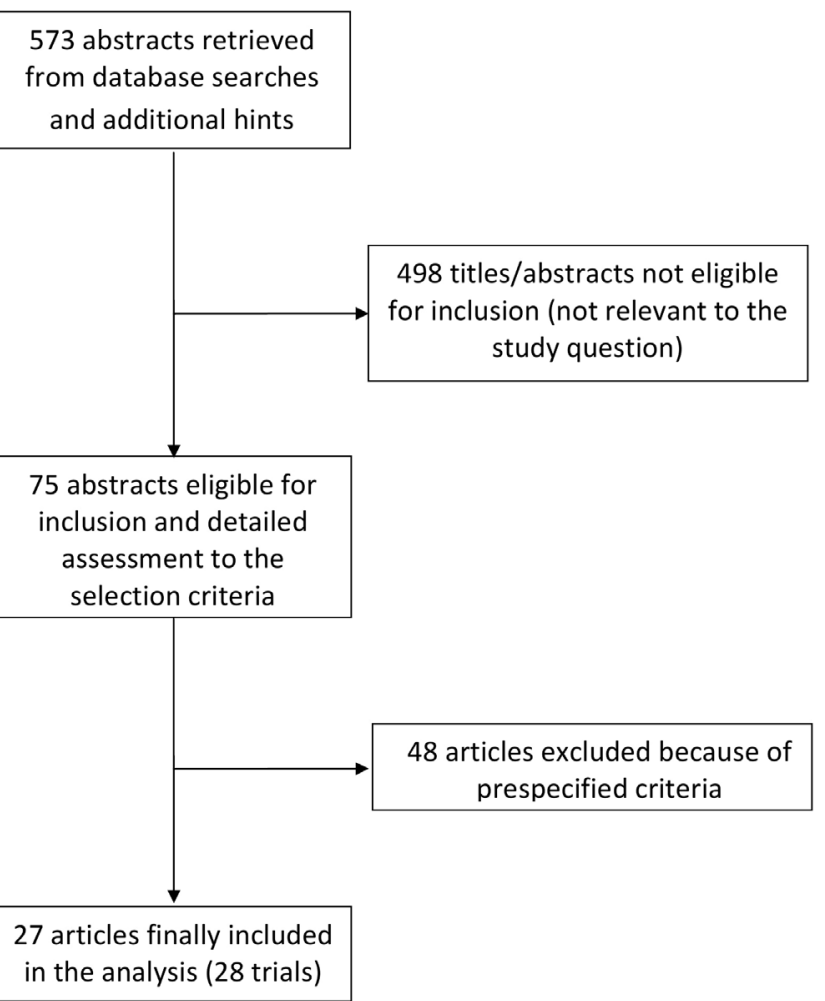

Figure 1. Flow diagram. The flow chart to select the final 27 manuscripts (28 trials).

doi:10.1371/journal.pone.0082913.g001
Collaboration and Preferred Reporting Items for Systematic Reviews and Meta-Analyses guidelines [16,19,20] (Checklist S1).

\section{Results}

\section{Study Characteristics}

Database searches, snowballing, and contacts with experts yielded a total of 573 articles. The flow chart to select the final 27 manuscripts (28 trials) [7-15,21-38] is detailed in figure 1, with major exclusions available in the supplemental material (Texts S2 and S3).

The 27 included manuscripts randomized 3,648 patients $(1,870$ to dexmedetomidine and 1,778 to control) (tables 1 and 2). Clinical heterogeneity was mostly due to setting, control treatment, and follow-up duration. Indeed, 13 trials used dexmedetomidine in a general ICU setting [8,12,13,26-29,31-34,37], ten in cardiac surgery ICU patients [7,9,10,14,15,21,24,25,30,35], four in major non-cardiac surgery ICU patients $[11,22,36,38]$ and one after caesarean section-eclampsia admitted to ICU [23]. Different techniques of dexmedetomidine administration were used: in 18 trials the continuous infusion was preceded by a loading dose that was often $1 \mathrm{mcg} / \mathrm{kg}[13,14,17,23,24,26,28-30,32,33,36]$ but that varied between 0.1 to $6 \mathrm{mcg} / \mathrm{kg}$ in other trials $[11,22,25,27,30,34,37,38]$. In other 6 trials only continuous infusion was used and ranged between 0.1 to $2.5 \mathrm{mcg} / \mathrm{kg} / \mathrm{h} \mathrm{[7-}$ $9,15,31,35]$ while in one trial only the loading dose was used [10] and one trial gave no details [12]. Study quality appraisal indicated that trials were of medium quality (Table S1); in particular 12 of them had a low risk of bias.

Six different comparators were identified: propofol in 11 study arms $[8,11,17,22,24,25,27,29,34,36,38]$, midazolam in 10 arms $[8,12,13,15,23,25,28,30,33,34]$, placebo in 5 arms [9,10,14,26,37], morphine in 2 arms [7,35], haloperidol [32] and lorazepam [31] in one study.

\section{Quantitative Data Synthesis}

Effect of dexmedetomidine on ICU stay and time to extubation. Overall analysis (figure 2; figure $\mathrm{S} 1$ ) showed that the use of dexmedetomidine was associated with a significant reduction in length of ICU stay $(\mathrm{WMD}=-0.79[-1.17$ to -0.40$]$ days, $p$ for effect $<0.001$, p for heterogeneity $<0.001, \mathrm{I}^{2}=93 \%$, $\mathrm{SMD}=-0.48[-0.78$ to -0.18$], \mathrm{p}$ for effect $=0.002, \mathrm{p}$ for heterogeneity $<0.001, \mathrm{I}^{2}=91 \%$; with 17 studies and 2,424 patients included) with results confirmed when subanalyses were performed on studies including patients undergoing elective surgery $(\mathrm{SMD}=-0.60[-1.05$ to -0.15$], \mathrm{p}$ for effect $=0.008$ with 8 studies included), in those including patients undergoing short term sedation (SMD $=-0.45[-0.81$ to -0.09$], \mathrm{p}$ for effect $=0.02$ with 11 studies included), in those including patients 


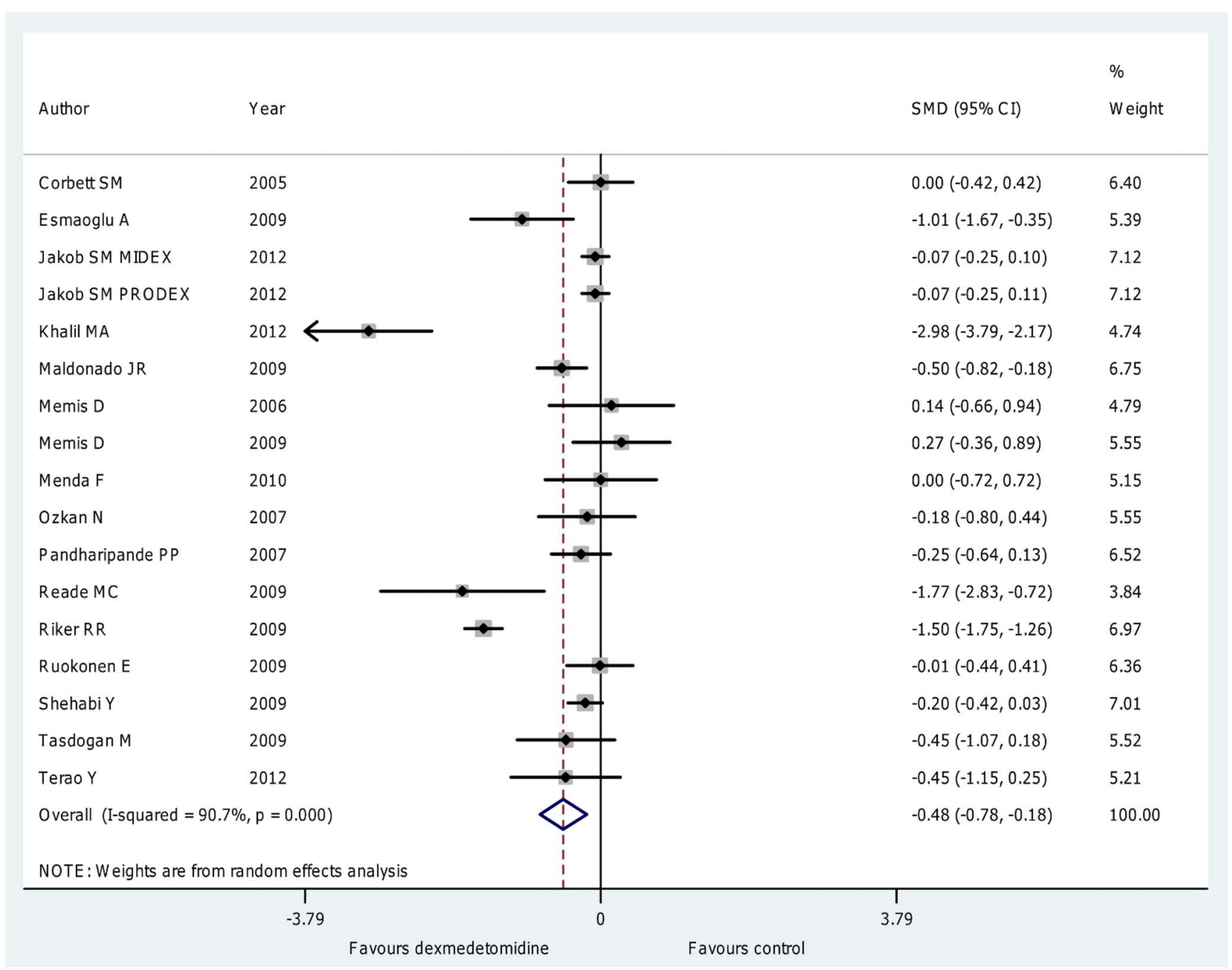

Figure 2. Forest plot for the length of ICU stay. Overall analysis showed that the use of dexmedetomidine was associated with a significant reduction in length of ICU stay $(S M D=-0.48[-0.78$ to -0.18$], p$ for effect $=0.002, p$ for heterogeneity $<0.001, I 2=91 \%$ with 17 studies and 2,424 patients included). $\mathrm{ICU}=$ intensive care unit; $\mathrm{Cl}=$ confidence interval; $\mathrm{SMD}=$ standardized mean difference; $\mathrm{N}=$ number; $\mathrm{SD}=$ standard deviation; Dex $=$ dexmedetomidine.

doi:10.1371/journal.pone.0082913.g002

receiving a loading dose $(\mathrm{SMD}=-0.58[-1.03$ to -0.13$]$, $\mathrm{p}$ for effect $=0.01$ with 11 studies included) and in those receiving low $(<0.7 \mu \mathrm{g} \mathrm{kg}-1 \mathrm{~h}-1)$ maintenance dose of dexmedetomidine $(\mathrm{SMD}=-0.62[-1.04$ to -0.20$], \mathrm{p}$ for effect $=0.004$ with 10 studies included) as detailed in table 3 .

The use of dexmedetomidine was also associated (figure 3; figure S2) with a significant reduction of time to extubation $(\mathrm{WMD}=-2.74[-3.80$ to -1.65$]$ hours, $\mathrm{p}$ for effect $<0.001, \mathrm{p}$ for heterogeneity $<0.001, \mathrm{I}^{2}=96 \%, \quad \mathrm{SMD}=-0.39 \quad[-0.66$ to $-0.11]$, p for effect $=0.005, \mathrm{p}$ for heterogeneity $<0.001$, $\mathrm{I}^{2}=93 \%$ with 24 studies and 3,478 patients included). Further subanalyses, detailed in table 3 , confirmed these findings in patients receiving short term sedation $(\mathrm{SMD}=-0.28[-0.49$ to $-0.07]$, $\mathrm{p}$ for effect $=0.009$ with 18 studies included), in those receiving a low $(<0.7 \mu \mathrm{g} \mathrm{kg}-1 \mathrm{~h}-1)$ maintenance dose $(\mathrm{SMD}=-0.30[-0.53$ to -0.07$], \mathrm{p}$ for effect $=0.009$ with 16 studies included) and in those undergoing elective surgery $(\mathrm{SMD}=-0.31[-0.52$ to -0.09$], \mathrm{p}$ for effect $=0.005$ with 17 studies included) with most of the positive finding coming from the cardiac surgery setting $(\mathrm{SMD}=-0.42[-0.75$ to -0.10$], \mathrm{p}$ for effect $=0.01$ with 10 studies included). The largest study [8] included in this meta-analysis was also the only one to report both median and mean values for mechanical ventilation. Since these data were skewed, we repeated the analyses including median instead of mean values and didn't find differences in pooled estimate results $(\mathrm{SMD}=-0.39,95 \%$ CI -0.66 to -0.12 , Isquare $=93 \%$ ).

Further subanalyses with the different comparators (propofol, midazolam, placebo and morphine) are detailed in supplemental material (TableS2 Table S3, Table S4 and Table S5) but were not informative with respect to ICU stay or time to extubation due to the paucity of trials included.

Visual inspection of funnel and scatter plots (figures 4 and 5; figures $\mathrm{S} 3$ and $\mathrm{S} 4$ ) did not identify a skewed or asymmetrical shape for the co-primary endpoints. Quantitative evaluation did not suggest a presence of publication bias, as measured by the Egger's test $(p=0.4$ for the length of ICU stay and $p=0.5$ for time to extubation) and Peters' test ( $p=0.6$ for the length of ICU stay and $\mathrm{p}=0.9$ for time to extubation). Since the funnel plots identified three outlier studies $[14,32,33]$ we repeated the analyses removing 


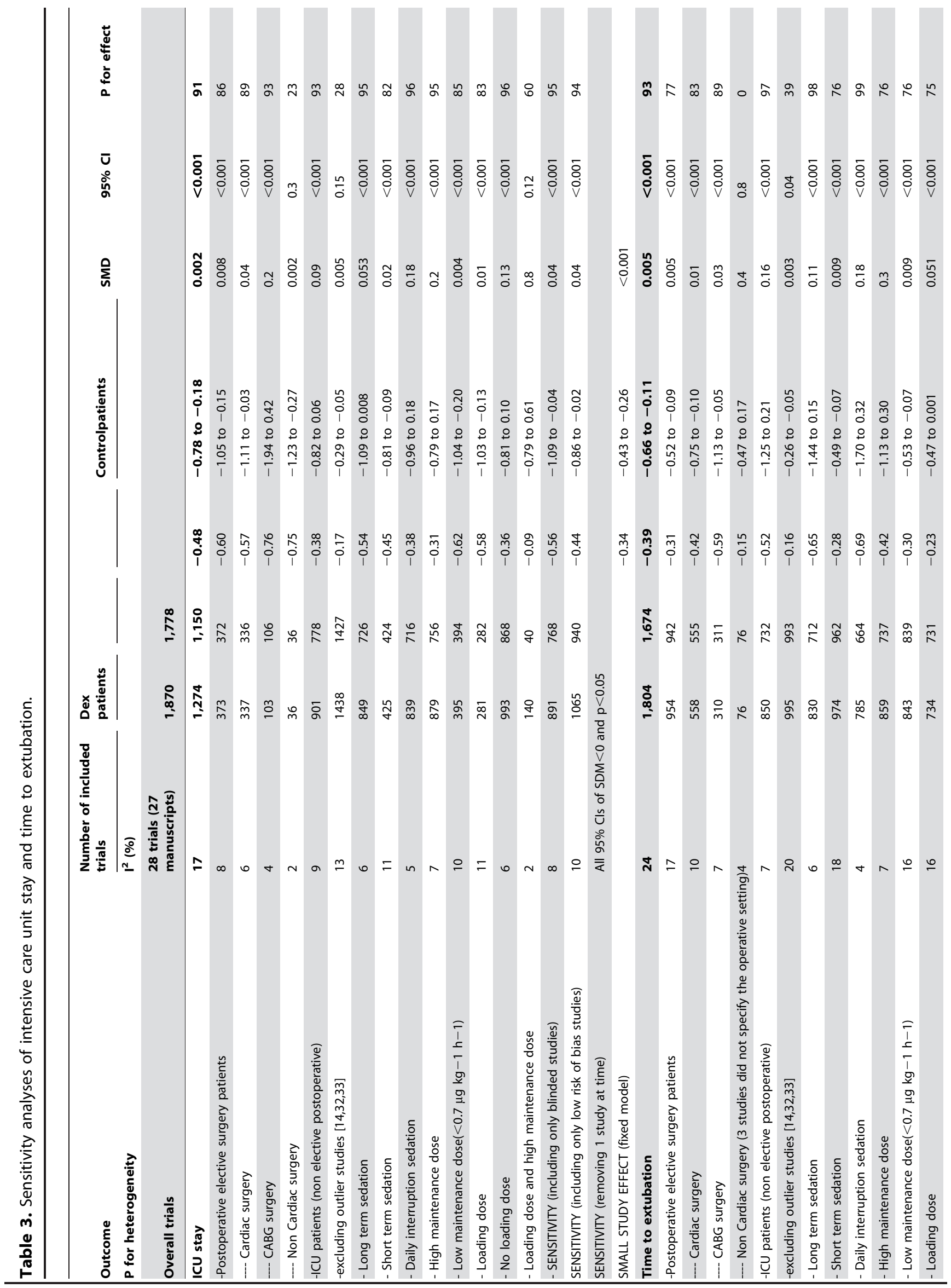




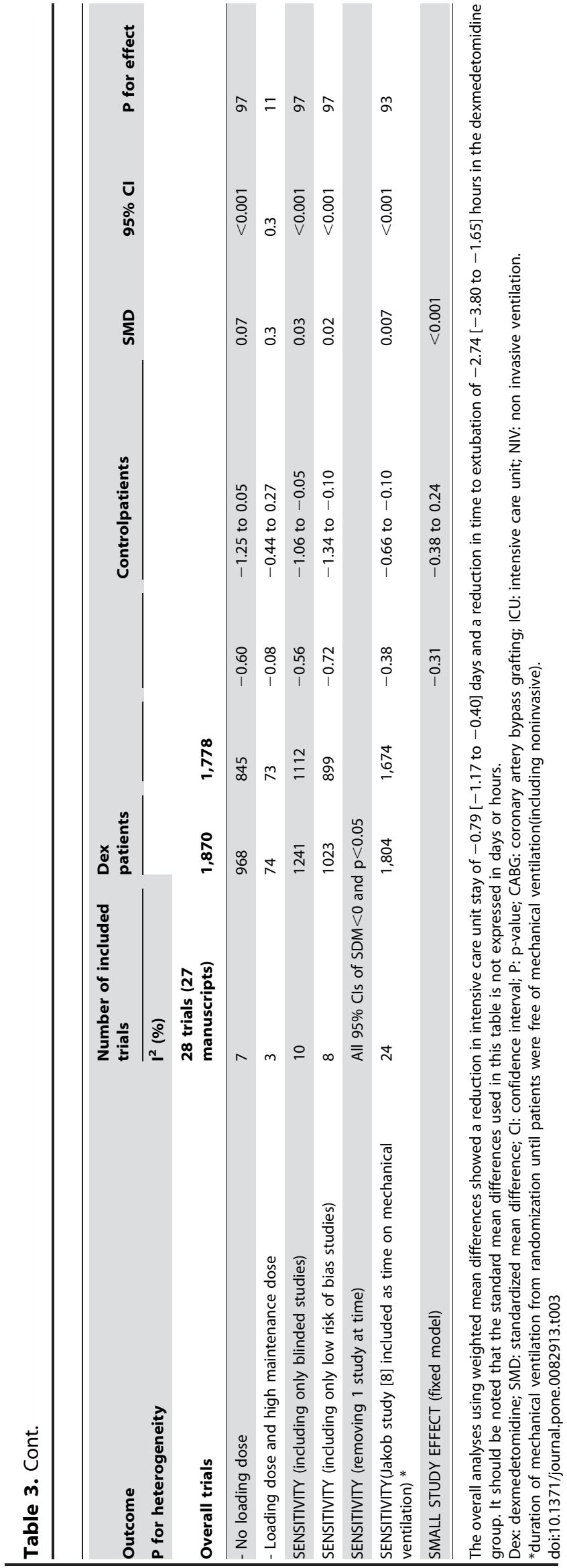

them and found that the statistically significant difference in ICU stay and time to extubation was maintained $(\mathrm{p}=0.005$ and $\mathrm{p}=0.003$ respectively $)$ and the heterogeneity reduced $\left(\mathrm{I}^{2}=28 \%\right.$ and $\mathrm{I}^{2}=39 \%$ respectively) (table 3 ).

Effect of dexmedetomidine on rescue doses of analgesic drugs, incidence of bradycardia, hypotension and mortality. Rescue doses of sedative or analgesic drugs were required less in the dexmedetomidine patients (892/1,459 [61\%] in the dexmedetomidine group versus $977 / 1,366$ [72\%] in the control arm, $\mathrm{p}=0.01$ with 14 studies included). A subanalysis showed that dexmedetomidine was associated with a significant reduction in the number of patients requiring rescue doses of analgesic drugs $(691 / 927$ [67\%] in the dexmedetomidine group versus $624 / 802[78 \%]$ in the control arm, $\mathrm{RR}=0.80[0.66$ to $0.98], p=0.03)$ with no differences in the number of patients requiring rescue doses of sedative drugs $(271 / 532$ [51\%] in the dexmedetomidine group versus $353 / 564$ [63\%] in the control arm, p =0.3) (Table 4).

Dexmedetomidine was associated with an increased rate of bradycardia (220/1,374 [16\%] in the dexmedetomidine group vs $64 / 1,246[5 \%]$ in the control group, $R R=2.43[1.88$ to 3.14$], p$ for effect $<0.001, p$ for heterogeneity $=0.9, \mathrm{I}^{2}=0 \%$ with 17 studies included) and with a trend towards an increased rate of hypotension (424/1,389 [31\%] in the dexmedetomidine group vs $279 / 1,266[22 \%]$ in the control group, $\mathrm{RR}=1.27[1.00$ to 1.61$]$, $\mathrm{p}$ for effect 0.052 , $\mathrm{p}$ for heterogeneity $<0.001, \mathrm{I}^{2}=62 \%$ with 19 studies included) (Table 4).

No difference in mortality was recorded at the longest follow-up available $(200 / 1,499$ [13\%] in the dexmedetomidine group vs $173 / 1,409[12 \%]$ in the control group, $\mathrm{RR}=1.00$ [0.84 to 1.21$], \mathrm{p}$ for effect $=0.9$ with 20 studies included). The univariate metaregression of average follow-up against log-risk mortality showed no significant effects for time on mortality $(n=20$, slope coefficient $=-0.001[-0.003$ to 0.001$], \mathrm{p}=0.31)($ Table 4$)$.

\section{Sensitivity analyses}

Estimate results from both random and fixed effect models were extremely similar (table 3); hence we excluded a considerable small study effect. Sensitivity analyses performed by sequentially removing each study and reanalysing the remaining dataset (producing a new analysis for each study removed), did not determine major changes in direction or magnitude of statistical findings, confirming the pooled effect of each co-primary endpoints (all SWD $<1$ ) and the statistical significance (all p of effect $<0$.05). Sensitivity analyses carried out with studies with low risk of bias confirmed the overall results of our work showing a reduction in length of ICU stay in dexmedetomidine versus control group $(\mathrm{SMD}=-0.44[-0.86$ to -0.02$] \mathrm{p}$ for effect $=0.04$, $\mathrm{p}$ for heterogeneity $<0.001, \mathrm{I}^{2}=94 \%$ with 10 studies and 2,005 patients included) and in time to extubation $(\mathrm{SMD}=-0.72$ $[-1.34$ to -0.10$]$, $\mathrm{p}$ for effect $=0.02, \mathrm{p}$ for heterogeneity $<0.001$, $\mathrm{I}^{2}=97 \%$ with 8 studies and 1,922 patients included). Sensitivity analyses carried out with blinded studies confirmed the overall results of our work showing a reduction in length of ICU stay in dexmedetomidine versus control group $(\mathrm{SMD}=-0.56[-1.09$ to $-0.04]$, $\mathrm{p}$ for effect $=0.04, \mathrm{p}$ for heterogeneity $<0.001, \mathrm{I}^{2}=95 \%$ with 8 studies and 1,659patients included) and a reduction in time to extubation $(\mathrm{SMD}=-0.56[-1.06$ to 0.05$]$, $\mathrm{p}$ for effect $=0.03, \mathrm{p}$ for heterogeneity $<0.001, \mathrm{I}^{2}=97 \%$ with 10 studies and 2,353 patients included). 


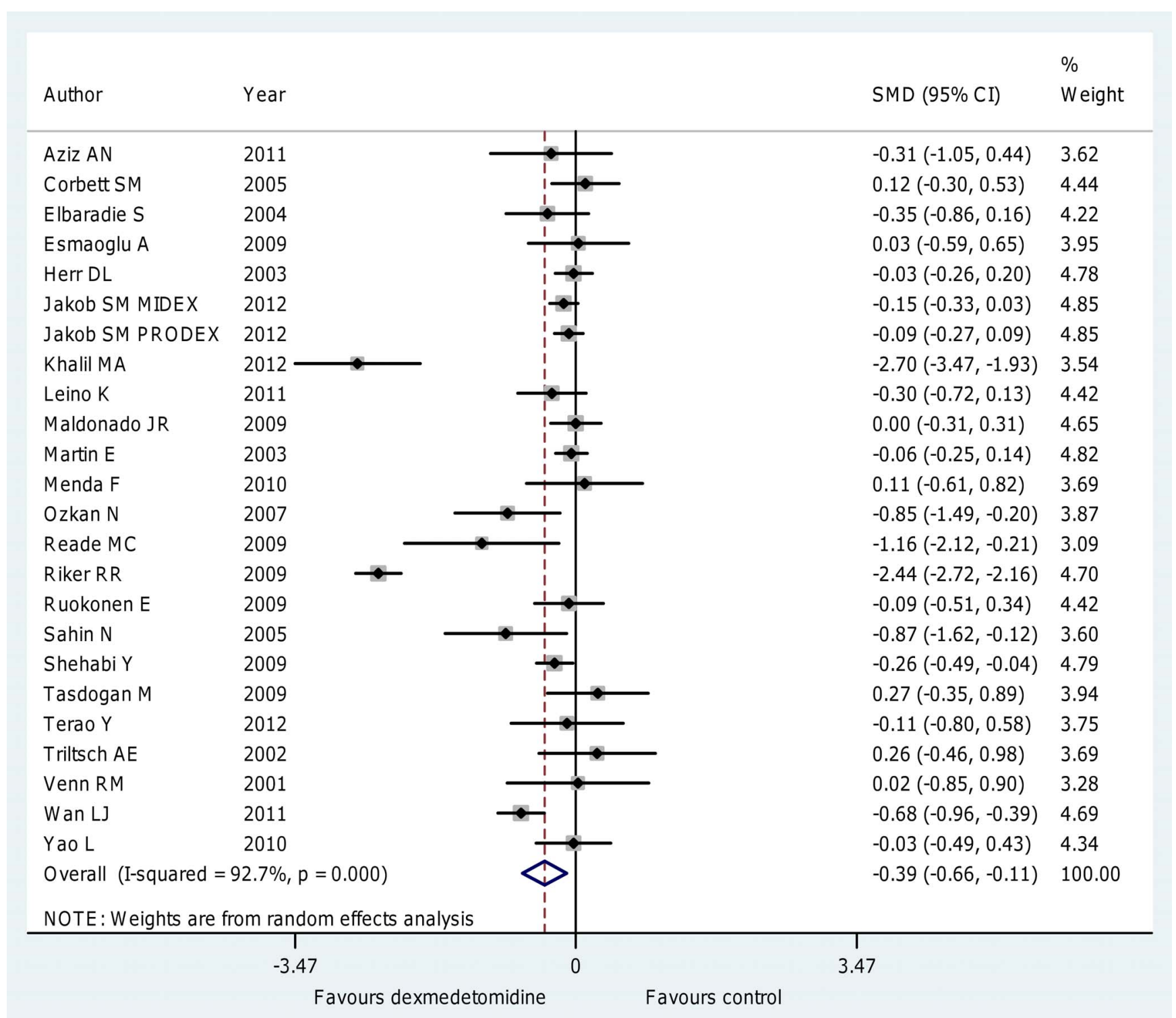

Figure 3. Forest plot for the time to extubation. Overall analysis showed that the use of dexmedetomidine was associated with a significant reduction of time to extubation (SMD $=-0.39[-0.66$ to -0.11$]$, p for effect $=0.005, \mathrm{p}$ for heterogeneity $<0.001,12=93 \%$ with 24 studies and 3,478 patients included). $\mathrm{Cl}=$ confidence interval; $\mathrm{SMD}=$ standardized mean difference; $\mathrm{N}=$ number; $\mathrm{SD}=$ standard deviation; Dex = dexmedetomidine. doi:10.1371/journal.pone.0082913.g003

\section{Discussion}

Our meta-analysis confirmed that dexmedetomidine is associated with a reduction in ICU stay and suggested that it might reduce the time of extubation when compared to other sedative or hypnotic agent. Even if dexmedetomidine is associated with an increase in the risk of bradycardia and with a trend toward an increased risk of hypotension, no detrimental effects on mortality were detected.

The ideal sedative agent should provide anticipated, predictable effects, rapid onset, and quick recovery. It should be easy to administer with no adverse events, no interaction with other drugs, no accumulation of metabolites and no withdrawal effects at the end of infusion. Unluckily an ideal sedative agent that can suit the need of all patients does not yet exist.

Dexmedetomidine is one of the most recently released intravenous agents for sedation in the ICU, though the drug started to be investigated more than 20 years ago. It was introduced in clinical practice in the United States in 1999 while the European Medicine Agency authorised its use for all 27 European member states in September 2011. It is an alpha2agonist and produces sedation acknowledged as "cooperative" or "arousable", which is different from the sedation "clouding of consciousness" induced by drugs acting on GABA receptors, such as midazolam or propofol [39]. Tan and Ho, in a previous metaanalysis updated on December 2009 [6] reported that when dexmedetomidine was compared with alternative sedative agents it was associated with a statistically significant reduction in length of ICU stay, but not in duration of mechanical ventilation. We updated their findings on February 2013 identifying eight recently published manuscripts [7-14] and one trial that was not identified in their systematic search [15], thus increasing the number of patients by $50 \%$ (up to 3,648 overall randomized patients included in our meta-analysis) and providing more robust safety data. By 


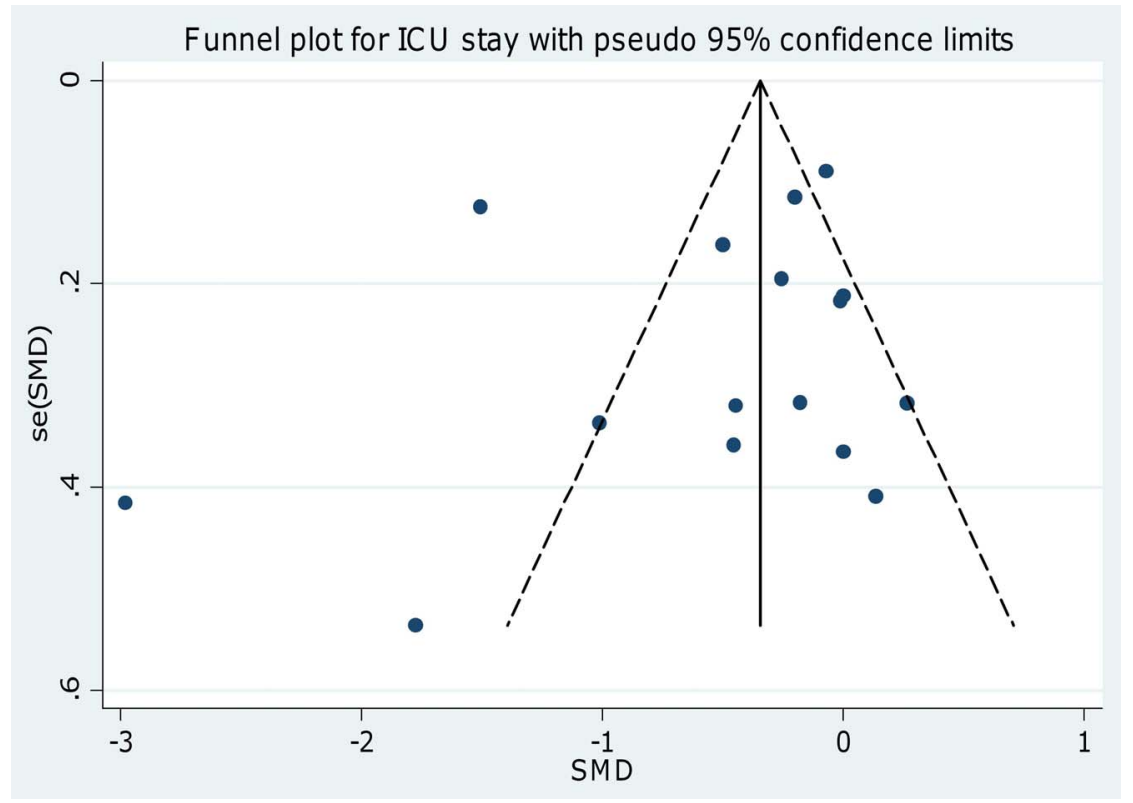

Figure 4. Funnel plot for the length of ICU stay. Visual inspection of funnel plots did not identify a skewed or asymmetrical shape for the coprimary endpoints. Quantitative evaluation did not suggest a presence of publication bias, as measured by the Egger's test $(p=0.4)$ and Peters' test $(p=0.6) . I C U=$ intensive care unit; $S E=$ standard error; $S M D=$ standardized mean difference.

doi:10.1371/journal.pone.0082913.g004

adding more patients data we were able to show, for the first time in a meta-analysis, that dexmedetomidine increases the rate of bradycardia when all trials are pooled together and also shows a trend towards an increase rate of hypotension. However, these side effects were not associated with differences in mortality (200/1499 $[13 \%]$ in the dexmedetomidine group vs $173 / 1409$ [12\%] in the control group, $\mathrm{p}=0.9$ with 20 studies included).

Dexmedetomidine decreases sympathetic nervous system activity and is therefore associated with an increase in cardiovascular adverse events. These effects may be most pronounced in patients with decreased autonomic nervous system response such as the elderly, diabetic patients, patients with chronic hypertension or severe cardiac disease such as valve stenosis or regurgitation, advanced heart block, severe coronary artery disease, or in patients who are already hypotensive and/or hypovolemic [40]. Therefore, in patients who depend on a high level of sympathetic tone or in patients with reduced myocardial function who cannot tolerate the decrease in sympathetic tone, loading doses of

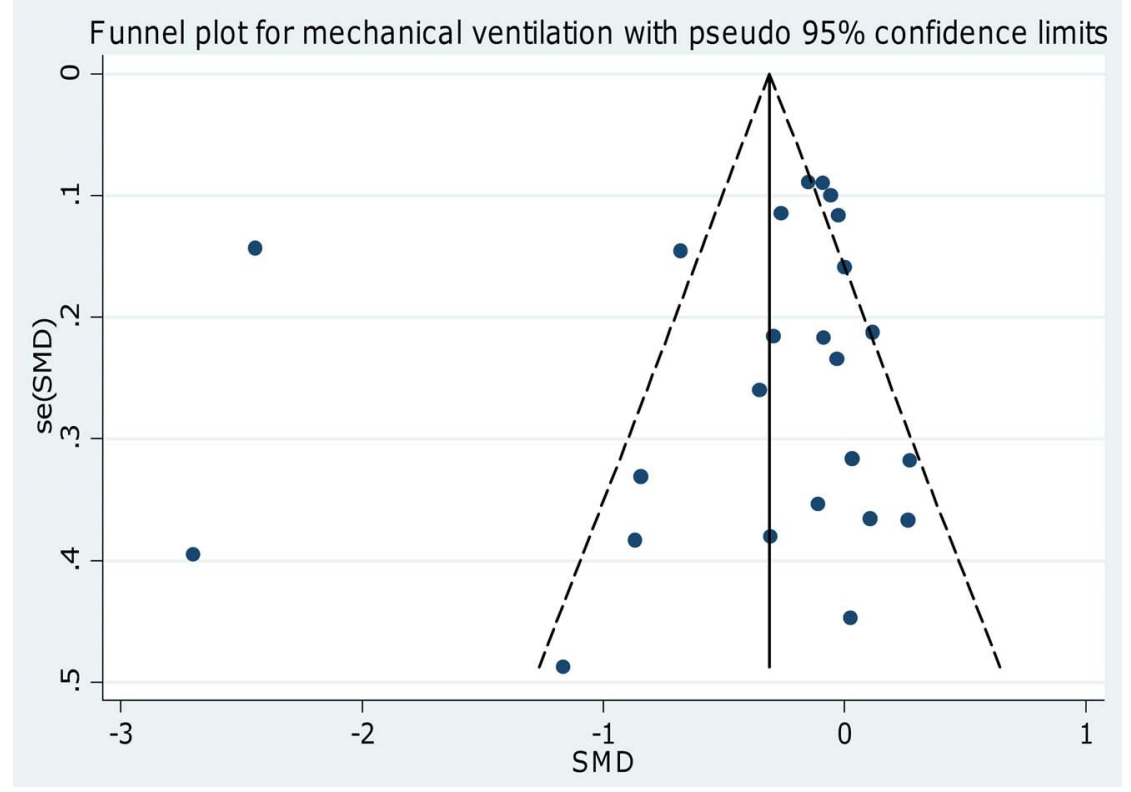

Figure 5. Funnel plot for the time to extubation. Visual inspection of funnel plots did not identify a skewed or asymmetrical shape for the coprimary endpoints. Quantitative evaluation did not suggest a presence of publication bias, as measured by the Egger's test $(p=0.5)$ and Peters' test $(p=0.9) . S E=$ standard error; $S M D=$ standardized mean difference.

doi:10.1371/journal.pone.0082913.g005 


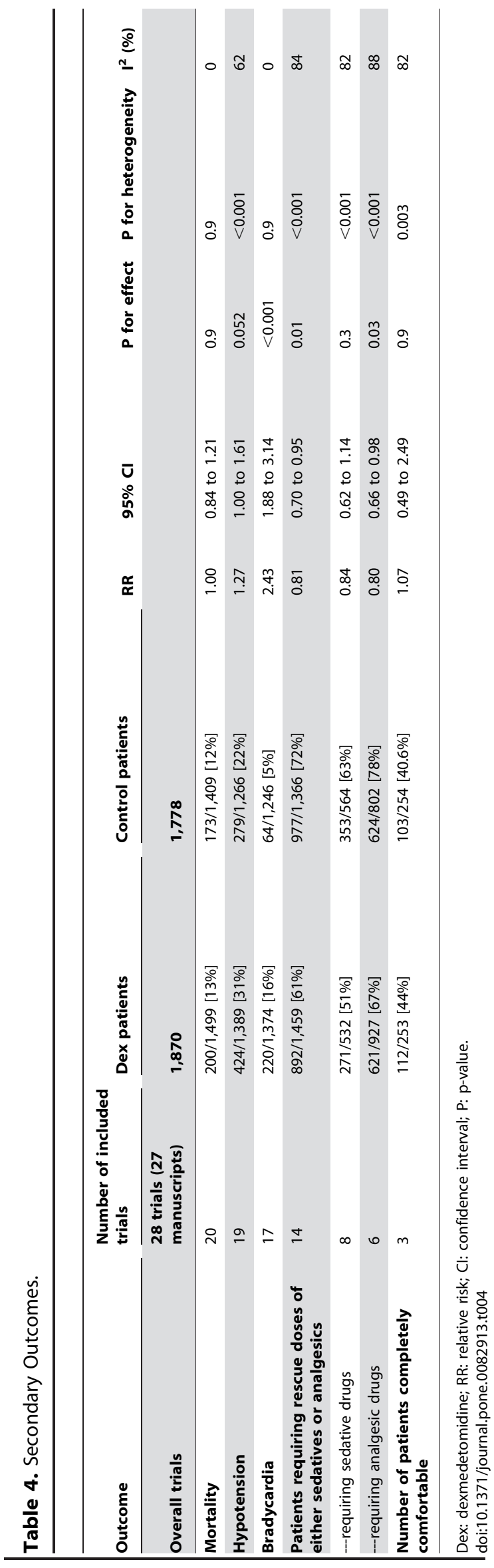

dexmedetomidine should be avoided. On the other side, the characteristics of dexmedetomidine to provide an ongoing sedation and sympathetic block could be beneficial in reducing early postoperative ischemic events in high-risk patients [41-42].

Intravenous administration of dexmedetomidine exhibits the following pharmacokinetic parameters: a rapid distribution phase with an half-life ( $\mathrm{t} 1 / 2 \alpha)$ of $6 \mathrm{~min}$, a terminal elimination half-life (t $1 / 2 \beta)$ of 2 hours, and a steady-state volume of distribution (Vss) of 118 litres. It presents linear kinetics when infused in the range of $0.2-0.7 \mu \mathrm{g} / \mathrm{kg} / \mathrm{h}$ for no more than 24 hours and undergoes almost complete biotransformation through direct glucuronidation and cytochrome P450 metabolism. Consequently it can accumulate in patients who are on $\mathrm{P} 450$ enzyme inhibitors, some of which are commonly used in ICU. Metabolites of biotransformation are excreted in the urine $(95 \%)$ and faeces [43].

\section{Limitations}

We acknowledge that this study has several limitations. The quality of the included studies is not high since only 13 of them were blind. Moreover we noted high heterogeneity between the included studies. The heterogeneity remained when sensitivity analyses on studies with low risk of bias where performed. It was abolished only removing three outliers studies cited above. Nonetheless we excluded the possible influence of small-study effects on the results of our meta-analysis comparing the fixed- and random-effects estimates of the treatment effect (table 3). The overall reduction in ICU stay and time to extubation may appear clinically modest, but it should be acknowledged that the largest study [8] had very conservative imputation rules (to worst outcome) and this might have softened our results.

\section{Conclusions}

Dexmedetomidine for sedation in mechanically ventilated critically ill adult patients seems to help to reduce time to extubation and ICU stay. The known side effects (increased incidence of bradycardia and a trend toward an increased risk of hypotension) had no effect on the overall mortality in this metaanalysis of all the RCTs published so far.

Larger, multicentre, randomized clinical trials, especially in long term sedated patients requiring mechanical ventilation, would be welcome to confirm these findings.

\section{Supporting Information}

\section{Checklist S1 PRISMA checklist.} (DOG)

Figure S1 Forest plot for the length of ICU stay using standard mean difference (days) instead of weighted mean difference (absolute value with no units of measurement). Overall analysis showed that the use of dexmedetomidine was associated with a significant reduction in length of ICU stay $(\mathrm{SMD}=-0.48[-0.78$ to -0.18$]$, $\mathrm{p}$ for effect $=0.002, p$ for heterogeneity $<0.001, \mathrm{I} 2=91 \%$ with 17 studies and 2,424 patients included). ICU = intensive care unit; $\mathrm{CI}=$ confidence interval $; \mathrm{SMD}=$ standardized mean difference; $\mathrm{N}=$ number; $\mathrm{SD}=$ standard deviation.

(TIF)

Figure S2 Forest plot for the time to extubation using standard mean difference (days) instead of weighted mean difference (absolute value with no units of measurement).. Overall analysis showed that the use of dexmedetomidine was associated with a significant reduction of time to extubation $(\mathrm{SMD}=-0.39[-0.66$ to -0.11$], \mathrm{p}$ for 
effect $=0.005, \mathrm{p}$ for heterogeneity $<0.001, \mathrm{I} 2=93 \%$ with 24 studies and 3,478 patients included). $\mathrm{CI}=$ confidence interval; $\mathrm{SMD}=$ standardized mean difference; $\mathrm{N}=$ number; $\mathrm{SD}=$ standard deviation

(TIF)

Figure S3 Scatter plot for ICU stay (TIF)

\section{Figure S4 Scatter plot for time to extubation} (TIF)

Table S1 Methodological quality summary: review authors' judgments about each methodological quality item for each included study.

(DOCX)

Table S2 Subanalysis with propofol as comparator drug (DOCX)

Table S3 Subanalysis with midazolam as comparator drug

(DOCX)

\section{References}

1. Paris A, Tonner PH (2005) Dexmedetomidine in anaesthesia. CurrOpinAnaesthesiol 18: 412-8.

2. Huupponen E, Maksimow A, Lapinlampi P, Särkelä M, Saastamoinen A, et al. (2008) Electroencephalogram spindle activity during dexmedetomidine sedation and physiological sleep. Acta Anaesthesiol Scand 52: 289-94.

3. Guo TZ, JiangJY, Buttermann AE, Maze M (1996) Dexmedetomidine injection into the locus ceruleus produces antinociception. Anesthesiology 84: 873-81.

4. Iirola T, Aantaa R, Laitio R, Kentala E, Lahtinen M, et al. (2011) Pharmacokinetics of prolonged infusion of high-dose dexmedetomidine in critically ill patients. Crit Care 15: R257.

5. Morsch RD, Ferri MB, Vasconcelos CP, Capone Neto A, Akamine N, et al. (2005) Dexmedetomidine as a sedative agent for more than 24 hours in acutely ill patients. Critical Care 9: P111.

6. Tan JA, Ho KM (2010) Use of dexmedetomidine as a sedative and analgesic agent in critically ill adult patients: a meta-analysis. Intensive Care Med 36: 92639.

7. Abd Aziz N, Chue MC, Yong CY, Hassan Y, Awaisu A, et al. (2011) Efficacy and safety of dexmedetomidine versus morphine in post-operative cardiac surgery patients. Int J Clin Pharm 33: 150-4.

8. Jakob SM, Ruokonen E, Grounds RM, Sarapohja T, Garratt C, et al. (2012) Dexmedetomidinevs midazolam or propofol for sedation during prolonged mechanical ventilation: two randomized controlled trials. JAMA 307: 1151-60.

9. Leino K, Hynynen M, Jalonen J, Salmenperä M, Scheinin H, et al. (2011) Renal effects of dexmedetomidine during coronary artery bypass surgery: a randomized placebo-controlled study. BMC Anesthesiol 11: 9.

10. Menda F, Köner O, Sayin M, Türe H, Imer P, et al. (2010) Dexmedetomidine as an adjunct to anesthetic induction to attenuate hemodynamic response to endotracheal intubation in patients undergoing fast-track CABG. Ann Card Anaesth 13: 16-21.

11. Terao Y, Ichinomiya T, Higashijima U, Tanise T, Miura K, et al. (2012) Comparison between propofol and dexmedetomidine in postoperative sedation after extensive cervical spine surgery. J Anesth 26: 179-86.

12. Wan LJ, Huang QQ Yue JX, Lin L, Li SH (2011) Comparison of sedative effect of dexmedetomidine and midazolam for post-operative patients undergoing mechanical ventilation in surgical intensive care unit. Zhongguo Wei Zhong Bing Ji Jiu Yi Xue 23: 543-6.

13. Yao L, Zhou XM, Zhao JJ (2010) The role of dexmedetomidine in treatment of serious patients in intensive care unit. Zhongguo Wei Zhong Bing Ji Jiu Yi Xue 22: 632-4.

14. Khalil MA, Abdel Azeem MS (2013) The impact of dexmedetomidine infusion in sparing morphine consumption in off-pump coronary artery bypass grafting. Semin CardiothoracVasc Anesth 17: 66-71.

15. Sahin N, Kabukcu H, Ozkan N, Titiz T (2005) The effects of postoperative dexmedetomidine and midazolam infusion on haemodynamics and sedation in patients after coronary artery bypass grafting. Eur J Anaesthesiol 22: 40.

16. Higgins JPT, Green S (2011) Cochrane handbook for systematic reviews of interventions. Version 5.1.0. Available: http://handbook.cochrane.org/ Accessed October 2013.

17. Begg CB, Mazumdar M (1994) Operating characteristics of a rank correlation test for publication bias. Biometrics 50:1088-101.

18. Peters JL, Sutton AJ, Jones DR, Abrams KR, Rushton L (2006) Comparison of two methods to detect publication bias in meta-analysis. JAMA 295: 676-80.
Table S4 Subanalysis with morphine as comparator drug

(DOCX)

Table S5 Subanalysis with placebo as comparator drug (DOCX)

Text S1 Full PubMed search strategy

(DOCX)

Text S2 Major exclusions

(DOCX)

\section{Text S3 References of the excluded studies}

(DOCX)

\section{Author Contributions}

Conceived and designed the experiments: LP TG PF AV CNN LC GL GF AZ. Performed the experiments: LP TG PF AV GNN LC GL GF AZ. Analyzed the data: LP TG PF AV GNN LC GL GF AZ. Contributed reagents/materials/analysis tools: LP TG PF AV GNN LC GL GF AZ. Wrote the paper: LP TG PF AV GNN LC GL GF AZ.

19. Biondi-Zoccai G, Lotrionte M, Landoni G, Modena MG (2011) The rough guide to systematic reviews and meta-analyses. HSR Proceedings in Intensive Care and Cardiovascular Anesthesia 3: 161-173.

20. Liberati A, Altman DG, Tetzlaff J, Mulrow G, Gøtzsche PC, et al. (2009) The PRISMA statement for reporting systematic reviews and meta-analyses of studies that evaluate healthcare interventions: explanation and elaboration. BMJ 339: b2700.

21. Corbett SM, Rebuck JA, Greene GM, Callas PW, Neale BW, et al. (2005) Dexmedetomidine does not improve patient satisfaction when compared with propofol during mechanical ventilation. Crit Care Med 33: 940-5.

22. Elbaradie S, El Mahalawy FH, Solyman AH (2004) Dexmedetomidine vs. propofol for short-term sedation of postoperative mechanically ventilated patients. J Egypt Natl CancInst 16: 153-8.

23. Esmaoglu A, Ulgey A, Akin A, Boyaci A (2009) Comparison between dexmedetomidine and midazolam for sedation of eclampsia patients in the intensive care unit. J Crit Care 24: 551-5.

24. Herr DL, Sum-Ping ST, England M (2003) ICU sedation after coronary artery bypass graft surgery: dexmedetomidine-based versus propofol-based sedation regimens. J Cardiothorac Vasc Anesth 17: 576-84.

25. Maldonado JR, Wysong A, van der Starre PJ, Block T, Miller C, et al. (2009) Dexmedetomidine and the reduction of postoperative delirium after cardiac surgery. Psychosomatics 50: 206-17.

26. Martin E, Ramsay G, Mantz J, Sum-Ping ST (2003) The role of the alpha2adrenoceptor agonist dexmedetomidine in postsurgical sedation in the intensive care unit. J Intensive Care Med 18: 29-41.

27. Memis D, Dökmeci D, Karamanlioglu B, Turan A, Türe M (2006) A comparison of the effect on gastric emptying of propofol or dexmedetomidine in critically ill patients: preliminary study. Eur J Anaesthesiol 23: 700-04.

28. Memis D, Hekimoğlu S, Vatan I, Yandim T, Yüksel M, et al. (2007) Effects of midazolam and dexmedetomidine on inflammatory responses and gastric intramucosal pH to sepsis, in critically ill patients. Br J Anaesth 98: 550-2.

29. Memis D, Kargi M, Sut N (2009) Effects of propofol and dexmedetomidine on indocyanine green elimination assessed with LIMON to patients with early septic shock: a pilot study. J Crit Care 24: 603-8.

30. Ozkan N, Sahin N, Karakaya Kabukcu H, Celikbilek G, Aydogdu Titiz T (2007) Comparison of the effects of dexmedetomidine with midasolam on haemodynamics and oxygen profile in patients undergoing coronary artery bypass grafting. Gogus-Kalp-Damar Anestezive Yogun Bakim Dernegi Dergisi 13:161-168.

31. Pandharipande PP, Pun BT, Herr DL, Maze M, Girard TD, et al. (2007) Effect of sedation with dexmedetomidinevslorazepam on acute brain dysfunction in mechanically ventilated patients: the MENDS randomized controlled trial. JAMA 298: 2644-2653.

32. Reade MC, O'Sullivan K, Bates S, Goldsmith D, Ainslie WR, et al. (2009) Dexmedetomidine vs. haloperidol in delirious, agitated, intubated patients: a randomised open-label trial. Crit Care 13: R75.

33. Riker RR, Shehabi Y, Bokesch PM, Ceraso D, Wisemandle W, et al. (2009) Dexmedetomidinevs midazolam for sedation of critically ill patients: a randomized trial. JAMA 301: 489-99.

34. Ruokonen E, Parviainen I, Jakob SM, Nunes S, Kaukonen M, et al. (2009) Dexmedetomidine versus propofol/midazolam for long-term sedation during mechanical ventilation. J Intensive Care Med 35: 282-90.

35. Shehabi Y, Grant P, Wolfenden H, Hammond N, Bass F, et al. (2009) Prevalence of delirium with dexmedetomidine compared with morphine based 
therapy after cardiac surgery: a randomized controlled trial (DEXmedetomidineCOmpared to Morphine-DEXCOM Study). Anesthesiology 111: 1075-84.

36. Tasdogan M, Memis D, Sut N, Yuksel M (2009) Results of a pilot study on the effects of propofol and dexmedetomidine on inflammatory responses and intraabdominal pressure in severe sepsis. J Clin Anesth 21: 394-400.

37. Triltsch AE, Welte M, von Homeyer P, Grosse J, Genähr A, et al. (2002) Bispectral index-guided sedation with dexmedetomidine in intensive care: a prospective, randomized, double blind, placebo-controlled phase II study. Crit Care Med 30: 1007-14.

38. Venn RM, Grounds RM (2001) Comparison between dexmedetomidine and propofol for sedation in the intensive care unit: patient and clinician perceptions. Br J Anaesth 87: 684-90.

39. Aho M, Erkola O, Kallio A, Scheinin H, Korttila K (1993) Comparison of dexmedetomidine and midazolam sedation and antagonism of dexmedetomidine with atipamezole. J Clin Anesth 5: 194-203.
40. Gertler R, Brown HC, Mitchell DH, Silvius EN, Mitchell DH (2001) Dexmedetomidine: a novel secative-analgesic agent. Proc (Bayl Univ Med Cent) 14: 13-21.

41. Talke P, Li J, Jain U, Leung J, Drasner K, et al. (1995) Effects of perioperative dexmedetomidine infusion in patients undergoing vascular surgery. The Study of Perioperative Ischemia Research Group. Anesthesiology 82: 620-633.

42. Chorney SR, Gooch ME, Oberdier MT, Keating D, Stahl RF (2013) The safety and efficacy of dexmedetomidinefor postoperative sedation in the cardiac surgery intensive care unit. HSR Proc Intensive Care Cardiovasc Anesth 5(1): $17-24$.

43. Yazbek-Karam VG, Aouad MM (2006) Perioperative uses of dexmedetomidine. Middle East J Anesthesiol 18: 1043-58. 